\title{
Concrete filled tubular arch modified-VFT bridge and its LLSI analysis
}

\author{
Zhihua Xiong1, a ,Jun Li ${ }^{2}$, b Sishun Wang ${ }^{2}$, Yuqing Liu', Haohui Xin ${ }^{1}$ \\ ${ }^{1}$ Department of Bridge Engineering, Tongji University, Shanghai, 200092, China \\ ${ }^{2}$ CCCC First Highway Consultants., Co., Ltd, Xi'an, 710075, China \\ axiongzhihua_2013@126.com, b437098545@qq.com
}

Keywords: composite bridge, arch bridge, VFT, structural efficiency.

Abstract. Concrete filled tubular arch bridge was widely used in China. The large dead weight and non-integrity of prestressed concrete deck above the arch went against the durability and bridge seismic design. Modified verbundfertigteil (VFT) was proposed as deck in the arch bridge. Modified VFT girder was convenient to fabricate and was light-weighted. Structural analysis was investigated and it proved that modified VFT was an economic solution. Live loaded structural index (LLSI) was proposed to evaluate the steel bridge's efficiency between different structural schemes.

\section{Introduction}

Deck arch bridge was built a lot in Southwest region in China since its excellent structural performance and aesthetic profile [1]. However, the tradition deck arch bridge was usually prestressed concrete beam and divided into several segments in the deck with expansion joints. The dead weight of the PC deck was huge and enlarged the section of the arch, on the mean time, these joints made a high bill for the maintenance [2]. In terms of durability, the scheme of an integral deck is preferred than un-continuous. Based on the problem above, a novel design scheme of the concrete filled arch bridge is proposed which solves the un-continuous deck issue and presents an economic solution. In the preliminary design of steel bridge, several different structures were compared to select the tender scheme, overall stiffness of the structure was usually evaluated by the deflection of the traffic load. However, the important economic factor- material cost was not involved. From this point of view, live loaded structural index (LLSI) was proposed in this article. LLSI incorporated the steel material cost. It reflected the efficiency of the bridge structure. It would be elaborated and implemented in the latter concrete filled tubular arch-modified VFT (CFTA-MVFT) bridge design.

\section{Concrete filled tubular arch(CFTA)-Modified VFT (MVFT) girder bridge design scheme}

VFT girder was a composite beam included precast concrete panel and steel beam, the typical sections were listed as Fig.1 [3-5]. While for the deck arch bridge, the author modified the section as Fig.2 for the convenience and safety of construction on the arch. MVFT was hoisted on to the pillar-cap. MVFT was entirely fabricated in the mill. The brief procedures of the fabrication included: girder fabrication; rebars make-up; connection rebar located in the girder; casting concrete. For the small and medium span deck arch bridge, deck girder length was usually less than 30 meters per span, which could be lifted onto the arch, it was a leap for the fast construction of deck arch bridge.

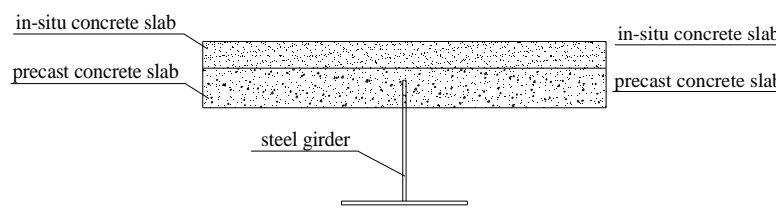

(a) plate girder

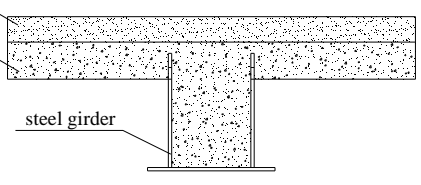

(b) tub girder

Fig. 1 Typical VFT section 


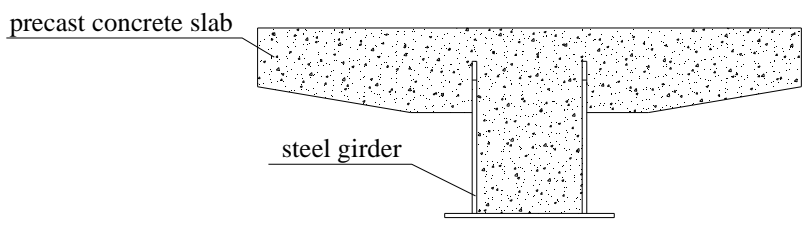

Fig. 2 MVFT section

\section{A CFTA-MVFT Bridge tender design}

The tender design was a deck arch bridge across the highway presented in Fig.3. The length of main span was $60 \mathrm{~m}$. The rise of arch was $8 \mathrm{~m}$, which satisfied the net height demand under bridge. The main bridge carried 3 lanes and 1 pedestrian way. The width of deck was $12.5 \mathrm{~m}$. Arch axis was designed as a catenary curve, whose coefficient was 2.9. The concrete filled in arch tube and deck slab was C50. The deck was MVFT girder proposed in section 2. The MVFT section was shown in Fig.4. Steel girder bottom flange and web were made of $70 \times 16 \mathrm{~mm}$ and $60 \times 14 \mathrm{~mm}$ respectively. Principle construction stage could be classified as: assembling and mounting the arch; pouring the concrete in the tubular arch; installing the pillar on the arch and lifting the MVFT, pouring the 13 meters in-situ girder segment on the arch crown.

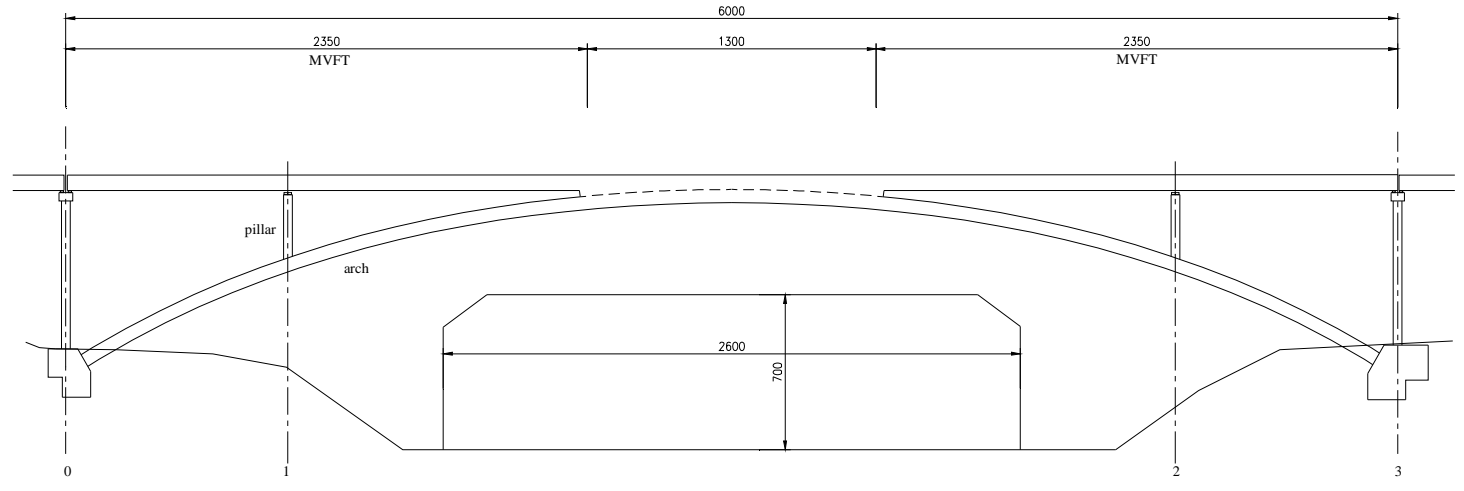

Fig. 3 CFTA-MVFT general layout (unit:cm)

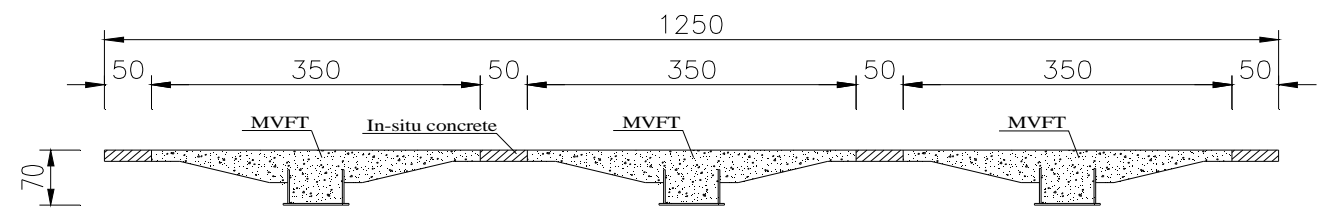

Fig. 4 MVFT section in the deck (unit:cm)

\section{Structural analysis}

The main bridge was modeled by CSIbridge as a spatial structure where all the components were defined as beam elements (Fig.5). The construction stages were considered in the model. Live loads were City A according to Chinese code. Temperature gradient was also applied according to Chinese code. Environment temperature changes were $+39^{\circ} \mathrm{C}$ and $-15^{\circ} \mathrm{C}$. Combinations of load were checked under the ultimate limit states (ULS) and the service limit states (SLS). Governing combination was ULS for the arch.

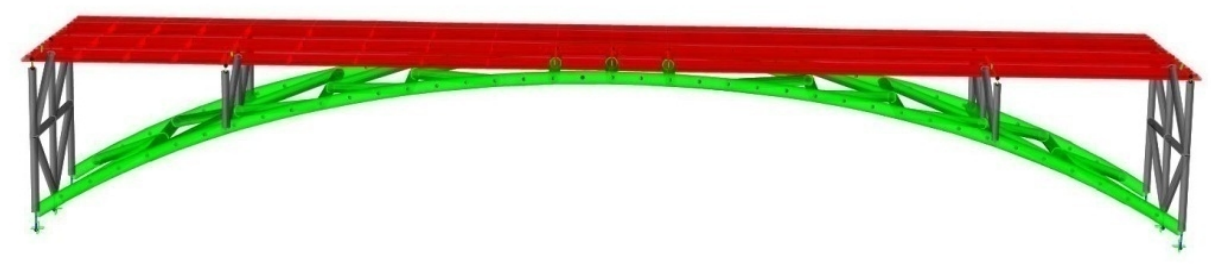

Fig. 5 3-D FEM model 


\section{Global stiffness}

The stiffness of entire bridge was checked under the live load without impact factor, which resulted in a maximum vertical displacement of $7.5 \mathrm{~cm}$ of the arch.

\section{Arch rib response}

The maximum axial force and bending moments under ULS were shown in Fig.6-7. The maximum axial compressive force was $9751.6 \mathrm{kN}$ at the spring point. The maximum moment force was 4143.3 $\mathrm{kN} \mathrm{m}$ at the arch crown.

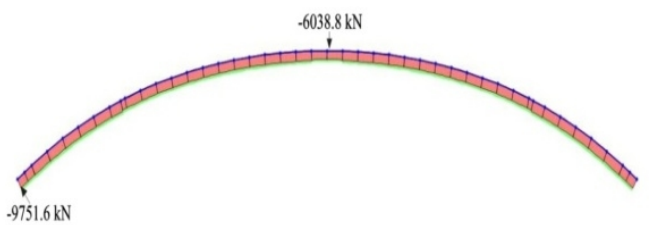

Fig. 6 arch axial force

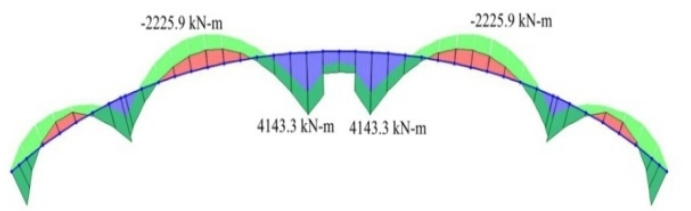

Fig. 7 arch moment

\section{MVFT internal forces and resistance strength}

Moment distribution under ULS was plotted in Fig.8. The maximum sag moment $(5597.8 \mathrm{kN} \mathrm{m})$ was near the quarter of arch and the maximum hogging moment $(-4395.5 \mathrm{kN} \mathrm{m})$ was on top of the $2 \#$ pillar. The strength resistance was predicted using ACI rules. The maximum internal forces were covered in the strength envelope as shown in Fig.9.

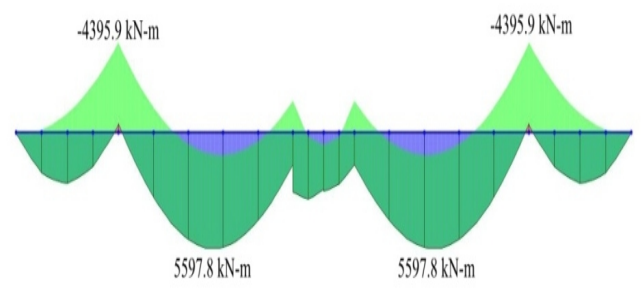

Fig. 8 MVFT moment

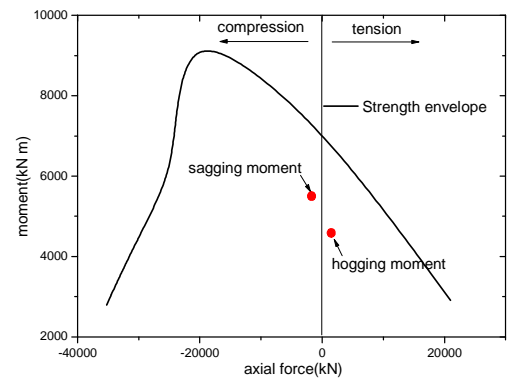

Fig. 9 MVFT strength envelope

\section{Live loaded structural index}

Alternative structural schemes were compared in preliminary design of steel bridge. As for the design scheme in the article, arch bridge and steel-concrete composite truss bridge were both considered and compared. For the convenience of the comparison and selection among the structures with different layout and steel cost, live loaded structural index (LLSI) was proposed in this paper. LLSI could be used in regular design for the evaluation of different steel bridges' structural efficiency. LLSI equation was written as:

$$
\begin{aligned}
& L L S I=\frac{k}{\eta} \\
& k=\frac{L}{\Delta} \\
& \eta=\frac{W}{L}
\end{aligned}
$$

In which $k$ denoted as span to deflection ratio, $\eta$ denoted steel weight to span ratio. An illustration of LLSI was made for the evaluation of different bridge structures. In the preliminary design, composite truss bridge was an alternative scheme, major dimension of which was: truss height $3.8 \mathrm{~m}$, bottom rectangular chord $600 \times 650 \mathrm{~mm}$, top rectangular chord $600 \times 300 \mathrm{~mm}$. The same live load was defined 
in the two analyzed models. LLSI of the CFTA-MVFT and truss bridge was 51.64 and 79.03 respectively.

\section{Conclusion}

CFTAS-MVFT bridge is suitable for the medium-span bridge and of aesthetic vision. CFTA-MVFT bridge deck was continous, which could decreased the expansion joint and the maintenance cost. MVFT is of economic efficiency and enough strength. LLSI proposed in the paper incorporates stiffness and steel cost. LLSI could be implemented in the evaluation of steel and composite bridges scheme. In terms of the same span, CFTA-MVFT bridge is lighter than the truss bridge which means less steel cost. However, the stiffness of truss bridge was larger than the CFTA-MVFT bridge.

\section{Acknowledgements}

This paper was financially supported by Highway Construction technology in High-altitude and permafrost region, part of National Science-Technology Support Plan funded by Ministry of Science and Technology of China (Contract No. 2014BAG05B05).

\section{References}

[1] Yan, G. and Yang, Z.H., 1997. Wanxian Yangtze Bridge, China. Structural Engineering International, 7(3), pp.164-166.

[2] Han, L.H., Li, W. and Bjorhovde, R., 2014. Developments and advanced applications of concrete-filled steel tubular (CFST) structures: Members. Journal of Constructional Steel Research, 100, pp.211-228.

[3] Magalhães, F., Cunha, Á. and Caetano, E., 2008. Dynamic monitoring of a long span arch bridge. Engineering Structures, 30(11), pp.3034-3044.

[4] Doss, W., Gebeshuber, A., Friedrich, N., Schmitt, V., Seidl, G. and Weizenegger, M., 2001. VFT-Bauweise-Entwicklung von Verbundfertigteilträgern im Brückenbau. Beton-und Stahlbetonbau, 96(4), pp.171-180.

[5] Schmitt, V., Seidl, G., Hever, M. and Zapfe, C., 2004. Verbundbrücke Pöcking-Innovative VFT -Träger mit Betondübeln. Stahlbau, 73(6), pp.387-393

[6] Liu, Y., Xiong, Z., Feng, Y. and Jiang, L., 2017. Concrete-filled rectangular hollow section X joint with Perfobond Leister rib structural performance study: Ultimate and fatigue experimental Investigation. STEEL AND COMPOSITE STRUCTURES, 24(4), pp.455-465 